\section{Evolution of Mammalian Diving Capacity Traced by Myoglobin Net Surface Charge}

Scott Mirceta, Anthony V. Signore, Jennifer M. Burns, Andrew R. Cossins, Kevin L. Campbell, Michael Berenbrink*

Introduction: Evolution of extended breath-hold endurance enables the exploitation of the aquatic niche by numerous mammalian lineages and is accomplished by elevated body oxygen stores and morphological and physiological adaptations that promote their economical use. High muscle myoglobin concentrations in particular are mechanistically linked with an extended dive capacity phenotype, yet little is known regarding the molecular and biochemical underpinnings of this key specialization. We modeled the evolutionary history of this respiratory pigment over 200 million years of mammalian evolution to elucidate the development of maximal diving capacity during the major mammalian land-to-water transitions.

Methods: We first determined the relationship between maximum myoglobin concentration and its sequence-derived net surface charge across living mammalian taxa. By using ancestral sequence reconstruction, we then traced myoglobin net surface charge across a 130-species phylogeny to infer ancestral myoglobin muscle concentrations. Last, we estimated maximum dive time in extinct transitional species on the basis of the relationship of this variable with muscle myoglobin concentration and body mass in extant diving mammals.

Results: We reveal an adaptive molecular signature of elevated myoglobin net surface charge in all lineages of mammalian divers with an extended aquatic history-from 16-g water shrews to $80,000-\mathrm{kg}$ whales - that correlates with exponential increases in muscle myoglobin concentrations. Integration of this data with body mass predicts $82 \%$ of maximal dive-time variation across all degrees of diving ability in living mammals.

Discussion: We suggest that the convergent evolution of high myoglobin net surface charge in mammalian divers increases intermolecular electrostatic repulsion, permitting higher muscle oxygen storage capacities without potentially deleterious self-association of the protein. Together with fossil body-mass estimates, our evolutionary reconstruction permits detailed assessments of maximal submergence times and potential foraging ecologies of early transitional ancestors of cetaceans, pinnipeds, and sea cows. Our findings support amphibious ancestries for echidnas, talpid moles, hyraxes, and elephants, thereby not only establishing the earliest land-to-water transition among placental mammals but also providing a new perspective on the evolution of myoglobin, arguably the best-known protein.

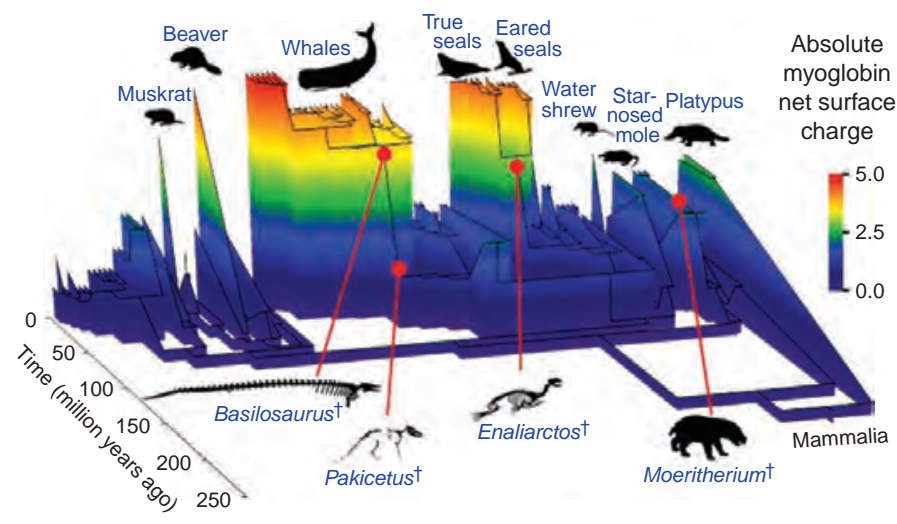

Evolutionary reconstruction of myoglobin net surface charge in terrestrial and aquatic mammals. The figure reveals a molecular signature of elevated myoglobin net surface charge in all lineages of living elite mammalian divers with an extended aquatic history (upper silhouettes). This signature is used here to infer the diving capacity of extinct species representing stages during mammalian land-towater transitions ( $\dagger$ ).

\section{FIGURES IN THE FULL ARTICLE}

Fig. 1. Myoglobin net surface charge and maximal muscle concentration in terrestrial, semiaquatic, and aquatic mammals.

Fig. 2. Relationship between electrophoretic mobility and modeled myoglobin net surface charge.

Fig. 3. Inferring maximal myoglobin concentrations through myoglobin net surface charge across the mammalian phylogeny.

Fig. 4. Details of myoglobin net surface charge evolution in major groups of diving mammals.

Fig. 5. Evolution of myoglobin net surface charge and aquatic habits in Afrotheria.

Fig. 6. Modeling diving capacity in ancestral whales, seals, and sea cows.

\section{SUPPLEMENTARY MATERIALS}

Supplementary Text

Figs. $\mathrm{S} 1$ to $\mathrm{S} 6$

Tables S1 to S7

References

ADDITIONAL RESOURCES

video.sciencemag.org/VideoLab/diving/ 


\section{Evolution of Mammalian Diving Capacity Traced by Myoglobin Net Surface Charge}

\author{
Scott Mirceta, ${ }^{1}$ Anthony V. Signore, ${ }^{2}$ Jennifer M. Burns, ${ }^{3}$ Andrew R. Cossins, ${ }^{1}$ \\ Kevin L. Campbell, ${ }^{2}$ Michael Berenbrink ${ }^{1 *}$
}

Extended breath-hold endurance enables the exploitation of the aquatic niche by numerous mammalian lineages and is accomplished by elevated body oxygen stores and adaptations that promote their economical use. However, little is known regarding the molecular and evolutionary underpinnings of the high muscle myoglobin concentration phenotype of divers. We used ancestral sequence reconstruction to trace the evolution of this oxygen-storing protein across a 130-species mammalian phylogeny and reveal an adaptive molecular signature of elevated myoglobin net surface charge in diving species that is mechanistically linked with maximal myoglobin concentration. This observation provides insights into the tempo and routes to enhanced dive capacity evolution within the ancestors of each major mammalian aquatic lineage and infers amphibious ancestries of echidnas, moles, hyraxes, and elephants, offering a fresh perspective on the evolution of this iconic respiratory pigment.

$\mathrm{E}$ xpert mammalian divers, such as Northern elephant seals and sperm whales, are able to hold their breath and actively forage in the oceans for periods of well over an hour $(1,2)$. Even for less proficient aquatic or amphibious mammals, maximal dive duration defines maxi mal foraging depth, enables the exploitation of new food sources, determines how far polar ma rine or temperate freshwater species can venture under ice cover, and limits how long they can stay submerged for predator evasion (3 5).

The fossil record has revealed highly conver gent changes in body, limb, and tail structures accompanying the secondary transitions of mam mals to an aquatic habitat (6). Comparative phys iological analyses of extant divers have further illustrated that the attendant reductions in the en ergetic costs of underwater locomotion are cou pled with greatly elevated body oxygen stores and their economical use $(4,7,8)$. At the onset of submergence, an enhanced dive response leads to cessation of breathing, reduced heart rate, and peripheral vasoconstriction. The latter largely iso lates nonessential organs from the central blood oxygen supply, which is spared for the oxygen sensitive brain and heart and exercising mus cles. Most dives stay aerobic in nature, but during dives approaching maximal capacity accumula tion of carbon dioxide and lactic acid may lead to severe acidosis (9). Maximal active dive time $\left(t_{\max }\right)$ has been linked to the maximal skeletal muscle concentration of myoglobin, $[\mathrm{Mb}]_{\max }$, which

${ }^{1}$ Institute of Integrative Biology, University of Liverpool, Liver pool L69 7ZB, UK. '2Department of Biological Sciences, Uni versity of Manitoba, Winnipeg, Manitoba R3T 2N2, Canada. ${ }^{3}$ Department of Biological Sciences, University of Alaska, An chorage, AK 99508, USA

*Corresponding author. E mail: michaelb@liv.ac.uk varies greatly among divers for poorly under stood reasons $(4,10,11)$.

Myoglobin $(\mathrm{Mb})$ of the sperm whale was the first protein characterized at the atomic level in Nobel prize winning work (12) and is perhaps the best studied of all proteins. Mammalian Mbs are small, 153 amino acid globular proteins whose primary to tertiary structures are highly conserved, giving rise to eight alpha helices that enclose a hydrophobic core containing the oxygen binding heme group and simultaneously provide a highly polar external surface. $\mathrm{Mb}$ is involved in the storage and facilitated diffusion of oxygen within muscle cells (13). It has a higher oxygen affinity than hemoglobin and is little affected by $\mathrm{pH}$ and other allosteric effectors. Although these biochem ical properties are conserved across terrestrial and aquatic mammals (14), $\mathrm{Mb}$ and its precursor, apo $\mathrm{Mb}$ (without the heme), are more stable against unfolding and aggregate less easily at high con centrations in aquatic relative to terrestrial mam mals, consistent with much higher expression yields of sperm whale $\mathrm{Mb}$ in Escherichia coli compared with Mbs of terrestrial mammals $(15,16)$.

We show that high $[\mathrm{Mb}]_{\max }$ values across all mammals are highly correlated with increased $\mathrm{Mb}$ net surface charge $\left(\mathrm{Z}_{\mathrm{Mb}}\right)$ obtained by modeling $\mathrm{Mb}$ primary structure onto the tertiary structure of the protein and using site specific, conserved ion ization constants. By using ancestral sequence reconstruction, we traced the evolution of $Z_{\mathrm{Mb}}$ and hence $[\mathrm{Mb}]_{\max }$ across the mammalian phy logeny. Combining this with allometric analysis of $t_{\max }$ and fossil body mass estimates, we re constructed the evolution of diving capacity across the major groups of mammalian divers.

\section{Results}

\section{Mb Net Surface Charge and Maximal Muscle Concentration}

$[\mathrm{Mb}]_{\max }$ of elite divers may exceed values in ter restrial mammals by factors of more than 30 , reach ing $100 \mathrm{mg} / \mathrm{g}$ of wet mass (Fig. 1A) or $133 \mathrm{mg} / \mathrm{ml}$ of water [assuming $75 \%$ (weight/weight) muscle water content]. High $[\mathrm{Mb}]_{\max }$ in divers is invar iably linked with an increase in $Z_{\mathrm{Mb}}$, at $\mathrm{pH} \quad 6.5$ from around +1 in terrestrial mammals to about +5 in elite divers (Fig. 1A). Although intracellular muscle $\mathrm{pH}$ in diving mammals is unknown, a similar pattern holds for $\mathrm{pH} \quad 6.0$ and 7.0 and thus likely holds over the range of physiological $\mathrm{pH}$ values (fig. S1) (17). Our estimates of $Z_{\mathrm{Mb}}$ close ly agree with the electrophoretic mobilities of pu rified Mbs from selected aquatic and terrestrial mammals (Fig. 2, A and B), confirming the re liability of modeling $Z_{\mathrm{Mb}}$ from $\mathrm{Mb}$ amino acid sequence and conserved tertiary structure and site specific ionization constants. Protein solubility is generally lowest around zero net surface charge, increasing toward both higher and lower net sur face charges (18). The positive $\mathrm{Z}_{\mathrm{Mb}}$ in elite divers may cause electrostatic repulsion and thereby help to reduce the tendency of $\mathrm{Mb}$ and/or apo $\mathrm{Mb}$ to
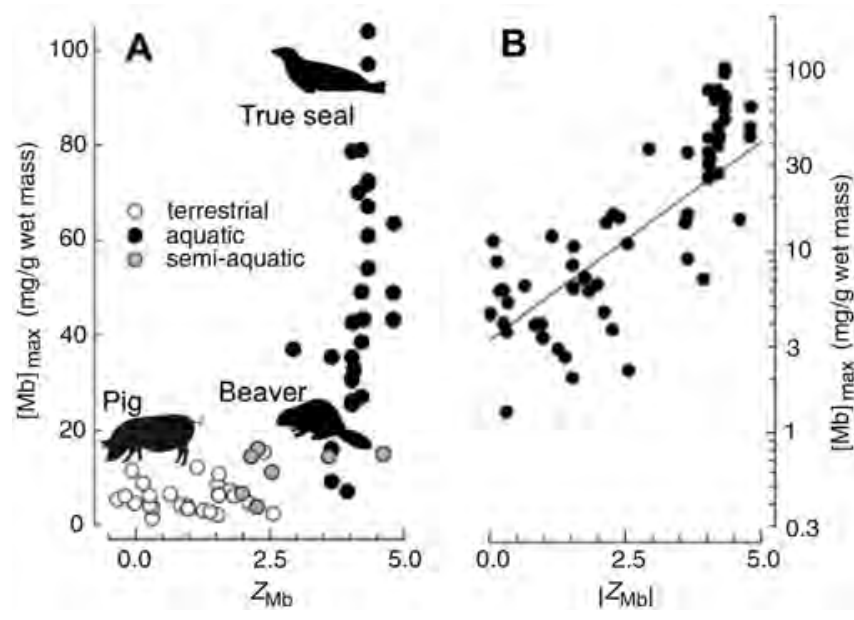

Fig. 1. Myoglobin net surface charge and maximal muscle concentration in terrestrial, semiaquatic, and aquatic mammals. (A) $[\mathrm{Mb}]_{\max }$ as a function of $Z_{\mathrm{Mb}}$ and (B) semilogarithmic plot of $[\mathrm{Mb}]_{\max }$ against । $Z_{M b}$; see text for the regression line (Eq. 1). $Z_{\mathrm{Mb}}$ was obtained by modeling at $\mathrm{pH}=6.5$. Silhouettes show representative terrestrial, semiaquatic, and aquatic mammals. 
self associate $(16,1921)$, which may otherwise interfere with its function in facilitated oxygen diffusion at high $\mathrm{Mb}$ concentrations in a heavily protein crowded sarcoplasm $(13,21,22)$.

After accounting for potential phylogenetic ef fects (23), the exponential increase in $[\mathrm{Mb}]_{\max }$ with absolute $\mathrm{Mb}$ net charge, $\left|Z_{\mathrm{Mb}}\right|$, is described by

$$
\log [\mathrm{Mb}]_{\max } \quad 0.220\left|Z_{\mathrm{Mb}}\right|+0.511
$$

$[P<0.001$, regression under an Ornstein Uhlenbeck process (Fig. 1B)]. This highly sig nificant relationship allows estimates of $[\mathrm{Mb}]_{\max }$ in species for which this information is unavail able (gaps in Fig. 3A) from their sequence derived $Z_{\mathrm{Mb}}$ values (Fig. 3B and table S1). Moreover, with use of ancestral sequence reconstruction, $Z_{\mathrm{Mb}}$ and hence $[\mathrm{Mb}]_{\max }$ can be estimated for extinct species along the mammalian phylogeny, allow ing insights into the evolution of mammalian muscle oxygen storage capacities over $200 \mathrm{mil}$ lion years of their evolutionary history (Fig. 3C and fig. S2).

\section{Highly Convergent Increase of Mb Net Surface Charge in Diving Mammals}

Strong, recurrent increases in $Z_{\mathrm{Mb}}$ arose by charge increasing substitutions at multiple sites and correspond with the adoption of both semi and fully aquatic lifestyles. For example, the early evolution of cetaceans shows an increase of $Z_{\mathrm{Mb}}$ from +1.1 at 54 million years ago $(\mathrm{Ma})$ to +3.7 at the time of the last common ancestor of baleen and toothed whales [36 Ma (Fig. 4A)]. This change in charge predicts a 3.5 fold increase in $[\mathrm{Mb}]_{\max }$ from $6 \mathrm{mg} / \mathrm{g}$ in early Eocene Pakicetus like ce taceans to $21 \mathrm{mg} / \mathrm{g}$ in late Eocene Basilosaurus like modern whale ancestors (Eq. 1). Our analysis suggests that the increase in $Z_{\mathrm{Mb}}$ was restricted to the cetacean lineage and did not occur in a com mon ancestor of whales and their closest living relatives, the semiaquatic hippopotamuses (Fig. 4A), implying a low degree of aquatic specialization in their last common ancestor.

Notably convergent increases in $Z_{\mathrm{Mb}}$ were also observed in the Phocidae (true seals) and Otarioidea (eared seals and walrus) after initial increases in common pinniped ancestors of the group (Fig. 4B). This finding indicates second ary, independent increases in physiological div ing capacity in both lineages after their divergence, concordant with fundamental differences in their mode of aquatic locomotion, body insulation, and foraging behaviors (24). Our analysis according ly suggests a maximal $Z_{\mathrm{Mb}}$ value of +3.0 for the late Oligocene/early Miocene stem pinniped Enaliarctos mealsi (25), corresponding to an [Mb $]_{\max }$ of $15 \mathrm{mg} / \mathrm{g}$ (Fig. 4B). This value is less than half of the value $(38 \mathrm{mg} / \mathrm{g})$ predicted by maximum parsimony based reconstruction of $[\mathrm{Mb}]_{\max }$ (fig. S3). Maximum parsimony fails to resolve the con vergent nature of $[\mathrm{Mb}]_{\max }$ increases during pinniped evolution, which illustrates the additional insights gained by our approach using the mo lecular signature of $Z_{\mathrm{Mb}}$.
Otaroids, phocids, and cetaceans evolved steep increases in $Z_{\mathrm{Mb}}$, which plateaued at values be tween about +4 and +5 , a likely functional op timum (Fig. 4, A and B). This is supported by the convergent evolution of similarly high $Z_{\mathrm{Mb}}$ values in both beaver and muskrat (Fig. 4C). Other lineages of semiaquatic mammals, such as the diminutive American water shrew and star nosed mole, show somewhat smaller increases in $Z_{\mathrm{Mb}}$, or they do not differ substantially from their non diving relatives (e.g., American mink and polar bear), matching their lower muscle $\mathrm{Mb}$ content (Figs. 1A and 3A) and more recent aquatic evo lutionary history (Fig. 4, B to D).

Elevated $[\mathrm{Mb}]_{\max }$ values in diving mammals are invariably accompanied by positive $Z_{\mathrm{Mb}}$ val ues, even though highly soluble proteins, such as serum albumin, are often characterized by strong ly negative $Z_{\mathrm{Mb}}$ values (26). However, the exist ence of already slightly positive $Z_{\mathrm{Mb}}$ in most terrestrial mammals (Fig. 1A) may have selected against the accumulation of negatively charged substitutions upon evolving a diving lifestyle, be cause this would initially decrease absolute net surface charge and hence likely also Mb solubility.

The observed charge increasing substitutions frequently involve replacements of neutral amino acids with fully positively charged Lys $(\mathrm{K})$ or weakly positively charged His $(\mathrm{H})$ residues, for example, cetaceans, pinnipeds, beaver, and muskrat (Fig. 4, A to D). Both of these are regarded as essential dietary amino acids for mammals (27), and this may underlie the delayed increase in muscle $\mathrm{Mb}$ concentration during development of diving mammals $(11,28)$, the submaximal $\mathrm{Mb}$ concentration in nonlocomotory muscles (28), and the relatively low $[\mathrm{Mb}]_{\max }$ values in baleen whales (table S1), which may be under relaxed selection pressure for elevated muscle oxygen stores because of lower mass specific metabolic rates at their gigantic size.

External surface His residues in $\mathrm{Mb}$ tend to have acid dissociation constants that result in only partial occupation of the proton binding site at physiological $\mathrm{pH}$ (table S2) and are therefore less efficient in increasing $\mathrm{Z}_{\mathrm{Mb}}$ relative to gains of fully positively charged Lys (K) and Arg (R) [or losses of fully negatively charged Asp (D) and Glu (E)]. His residues will, however, increase the specific buffer value of the protein $(29,30)$ and thereby whole muscle buffer power at the high $\mathrm{Mb}$ concentrations found in diving mammals. They will thus contribute to limiting $\mathrm{pH}$ changes, both during aerobic breath hold dives, where car bon dioxide still accumulates, and at the end of long dives, where profound lactic acidosis is ob served (9). This is in line with the largest number of additional His residues (four) having evolved in the Mbs of elite diving beaked whales and phocid seals (Fig. 4, A and B).

Charge increasing substitutions may occur at each of the external $\mathrm{Mb}$ surface positions (e.g., Fig. 4 and fig. S4). Of these, Asn (N) and Asp (D) at positions 12 and 122, respectively, are especial ly noteworthy, because they form a key stabilizing dimer contact in the recently resolved $\mathrm{x}$ ray crys
Fig. 2. Relationship between electropho-
retic mobility and modeled myoglobin
net surface charge. Native polyacrylamide gel of selected, purified mammalian Mbs at $\mathrm{pH}=6.0(\mathrm{~A})$ and correlation between electrophoretic mobility and modeled $\mathrm{Mb}$ net surface charge (B).

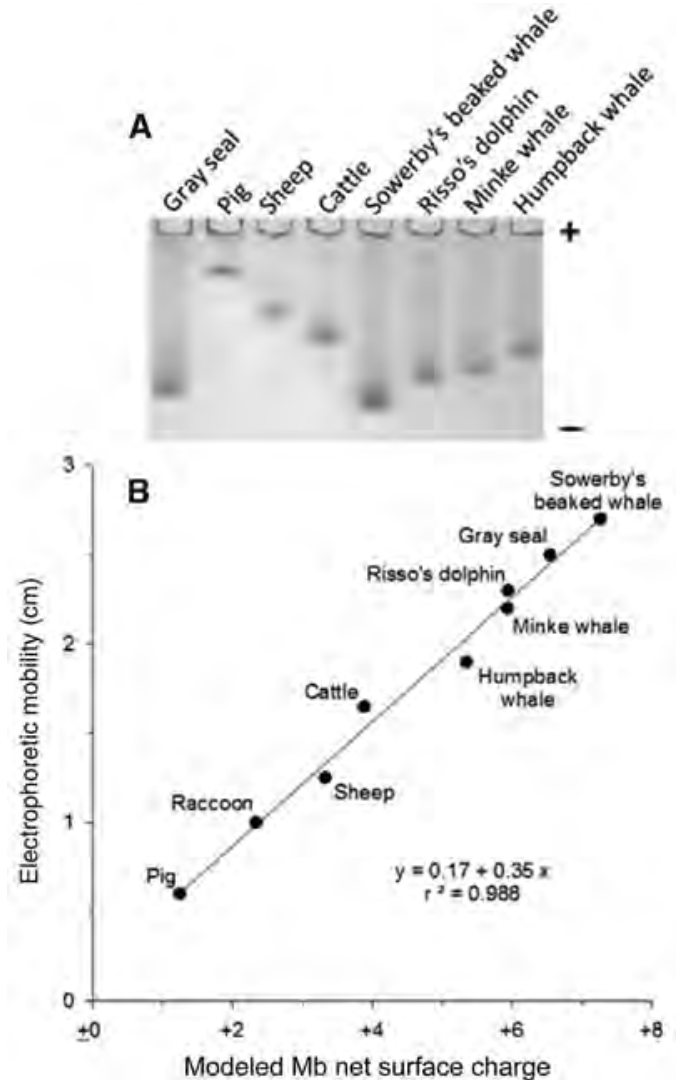


tallographic structure of dimeric horse $\mathrm{Mb}(20)$ and are replaced particularly frequently [five and three times independently, respectively (Fig. 4)]. Their recurrent substitution in diving mammals may help reduce the tendency for dimer formation at high concentrations, as is indeed observed for sperm whale $\mathrm{Mb}$ (16). High $\mathrm{Mb}$ concentrations and $\mathrm{Mb}$ dimer formation have been shown to lower its translational diffusion coefficient $(13,19,22)$, which may interfere with Mb's role in facilitated diffusion of oxygen inside muscle cells.

\section{Recent Amphibious Ancestries of Extant Terrestrial Mammals?}

The convergent increase of $Z_{\mathrm{Mb}}$ across living mammalian divers, including semiaquatic lineages such as water shrews and star nosed moles, cor roborates the predictive power of this molecular signature for inferring (semi)aquatic lifestyles. Thus, marked elevations in $Z_{\mathrm{Mb}}$ argue that an amphibious stage, still manifested in platypus and star nosed mole lineages, immediately predated evolution of modern terrestrial monotremes and fossorial moles, respectively (Fig. 4, D and E). This inference is in line with previous indepen dent suggestions of recent amphibious ancestries of echidnas (31) and talpid moles (32) using mor phological data sets. Modern echidnas and moles are accomplished burrowers, which, like high altitude mammals, are generally characterized by moderately elevated muscle Mb levels $(28,33)$. It is unlikely, however, that the strong ancestral increases in $Z_{\mathrm{Mb}}$ and therefore $[\mathrm{Mb}]_{\max }$ in these two lineages were associated with hypoxic sub terranean or high altitude environments, because $Z_{\mathrm{Mb}}$ is low or only moderately elevated in extant mammals with extended burrowing or high altitude evolutionary histories [e.g., burrowing naked and blind mole rats, aardvarks, and golden moles and high altitude black lipped pikas, guinea pigs, yaks, and Tibetan antelopes (Fig. 4 and table S1)].

An amphibious ancestry of Proboscidea has also been debated for more than a century on the basis of fossil anatomy, depositional environment, and isotope data (34 37). However, it is still unclear whether this has evolved independently from or in a common ancestor with sirenians (sea cows) (38). We have therefore determined $\mathrm{Mb}$ primary structures from all extant sirenian and proboscidean genera, together with the ex tinct woolly mammoth and Steller's sea cow. Our reconstruction of $Z_{\mathrm{Mb}}$ shows three consecu tive charge increasing substitutions already in the late Cretaceous/early Paleocene last com mon ancestor of sea cows, elephants, and hyraxes [paenungulates (Fig. 5)]. Increases of $Z_{\mathrm{Mb}}$ of such magnitude are otherwise only observed in lineages of expert divers [cetaceans, pinnipeds, beaver, and muskrat (Fig. 3)].

An amphibious ancestry of hyraxes may ap pear surprising; however, past hyracoid diversity was much richer than indicated by the three small bodied $(<5 \mathrm{~kg})$, strictly terrestrial genera of today, as illustrated by the at least two times larger Pliohyrax kruppii and the $390 \mathrm{~kg}$ Kvabebihyrax kachethicus from the Pliocene ( 2 to $5 \mathrm{Ma}$ ), for

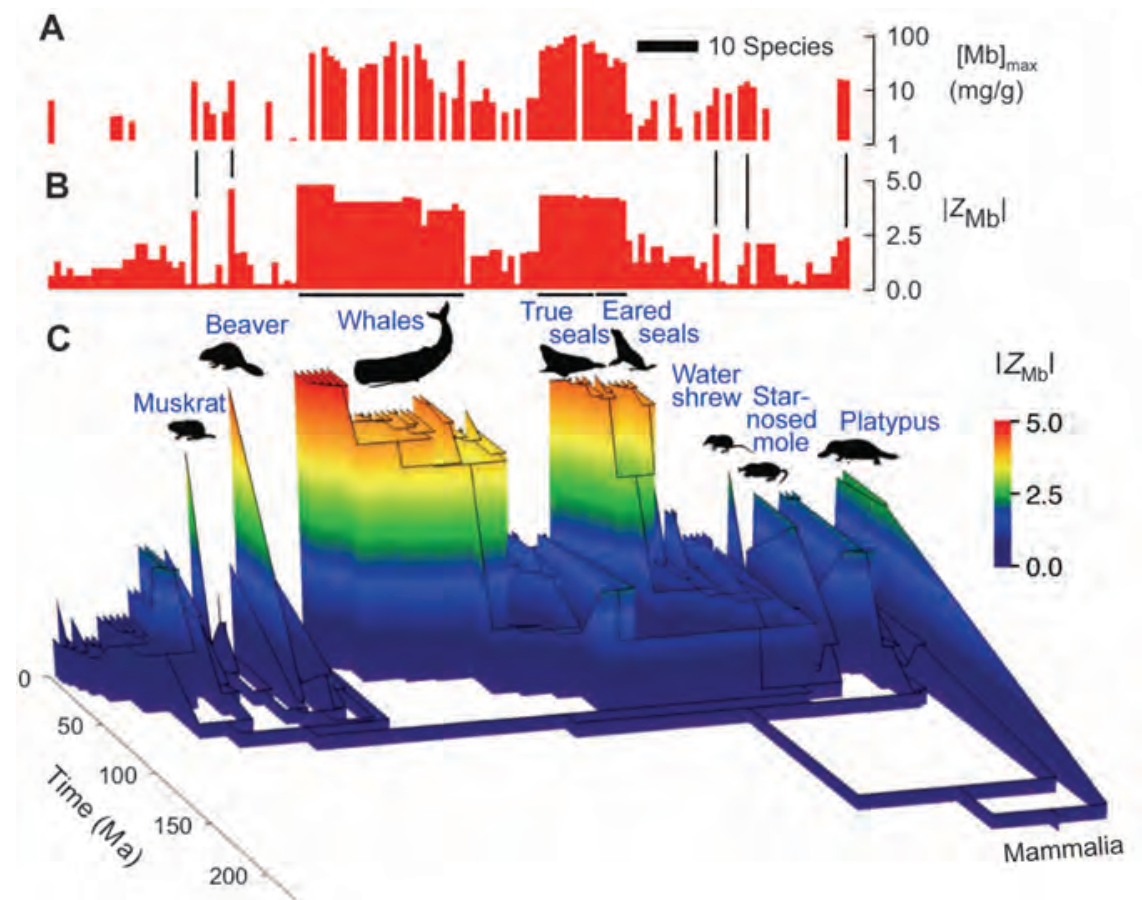

Fig. 3. Inferring maximal myoglobin concentrations through myoglobin net surface charge across the mammalian phylogeny. (A and B) The comparative availability of data on $[\mathrm{Mb}]_{\max }$ and $\mid Z_{\mathrm{Mb}} l_{\text {, }}$ respectively, in extant mammals. (C) Three-dimensional evolutionary reconstruction of $\left|Z_{M b}\right|(z$ axis, colorcoded, at $\mathrm{pH}=6.5)$ across their phylogeny $(x-y$ plane). Silhouettes and names indicate recent taxa of mammalian divers with elevated $Z_{\mathrm{Mb}}$ values.

which semiaquatic lifestyles have been proposed as long as a century ago $(39,40)$. Recent isotope evidence has further indicated a possible semi aquatic lifestyle for the late Eocene (37 Ma) Thyrohyrax meyeri and another, as yet unnamed, new hyracoid genus of similar age (34). The re construction of a high $Z_{\mathrm{Mb}}$ value in a hyracoid ancestor is not affected when ancestral sequence reconstruction is based on alternative phylogenetic hypotheses, such as hyraxes rather than sirenians comprising the sister group to proboscideans (41). This and recurrent gigantism [e.g., rhinoceros sized Titanohyrax ultimus (42)] calls for a reassessment of the lifestyle of other fossil hyraxes that have previously been considered unambiguously ter restrial (37).

Paenungulates contain two other lineages of large, extinct mammals, the enigmatic Desmostylia and Embrithopoda, for which semiaquatic life styles have also been proposed $(6,43)$. Taken together, these results suggest a shared second arily amphibious history of all paenungulates on the basis of the reconstructed molecular properties of their $\mathrm{Mb}$, establishing this clade as the earliest placental mammal radiation into the aquatic niche more than $64 \mathrm{Ma}$.

Our analysis also indicates that muscle $\mathrm{O}_{2}$ storage capacities in early amphibious probosci deans may have been even higher than in basal paenungulates, because two additional positive $\mathrm{Mb}$ charges are reconstructed in the stem proboscidean lineage, which are compensated by two negative charges in the last common ancestor of recent elephantids (Fig. 5). The most parsimonious evo lutionary scenario in light of fossil evidence is that $Z_{\mathrm{Mb}}$ continued to increase in early proboscideans before a secondary reduction. Thus, late Eocene/ early Oligocene semiaquatic Moeritherium (34) may have possessed a $Z_{\mathrm{Mb}}$ and muscle $\mathrm{O}_{2}$ storage capacity comparable to those found in modern pinnipeds and cetaceans (Figs. 4 and 5). The ob served charge changing substitutions in the Cape hyrax lineage are similarly consistent with a $Z_{\mathrm{Mb}}$ peak that coincided with the emergence of the possibly semiaquatic Thyrohyrax meyeri (34) (Fig. 5).

Within sirenians, we reconstructed a second ary reduction in $Z_{\mathrm{Mb}}$ from the late Cretaceous/ early Paleocene paenungulate ancestor toward modern forms, suggesting that semiaquatic early middle Eocene (50 Ma) sirenians, such as Pezosiren portelli (44), had higher muscle oxygen storage capacities than living forms, presumably because of the higher metabolic costs for functioning well both on land and in water in amphibious mam mals (45). The very low $Z_{\mathrm{Mb}}$ of extant, fully aquatic manatees is fully in line with a negligible muscle oxygen storage capacity (46) and is seemingly linked to a strongly reduced metabolic rate (oxy gen requirements) and a blunted dive response in these sluggish herbivores $(46,47)$. The second ary nature of these reductions is supported by observations on Steller's sea cow shortly before its extinction in 1768, where muscles "redder than the flesh of land animals" were noted and the 
animals exhibited intermittent cessation of blood flow from their wounds upon facial submergence (48), a sign of peripheral vasoconstriction and a dive response.

\section{Modeling Dive Capacity in Extinct Mammals}

Our evolutionary reconstruction of $\mathrm{Z}_{\mathrm{Mb}}$ allows estimation of $[\mathrm{Mb}]_{\max }$ and hence muscle oxygen storage capacities in extinct transitional forms rep resenting mammalian land to water transitions. To gain insight into the likely attendant maximal diving capacities, we have plotted all available $t_{\max }$ values for extant mammals, covering the full complement of mammalian diving abilities (e.g., from moose to elephant seals), against body masses ranging from $16 \mathrm{~g}$ water shrews to $80,000 \mathrm{~kg}$ blue whales (Fig. 6). Size influences $t_{\max }$, because oxygen storing organs in mammals (lung, blood, and muscle) generally increase isometrically with body mass, whereas metabolic rate increases with body mass exponents below 1.0, allowing larger mammals to deplete their oxygen stores more slowly $(10,49)$. Thus, the Eocene land to water transition of whales was accompanied by a pro gressive increase in body mass (Fig. 6A and table S3). However, Fig. 6 illustrates that, even at con stant body mass, $t_{\max }$ varies greatly in living mam mals. This variation can principally be ascribed to species specific deviations from the allometric predictions of diving metabolic rate and/or avail able oxygen stores. The former is mostly unknown even for extant mammals, and the latter depends on the complex depletion dynamics of variably sized lung, blood, and muscle oxygen reservoirs
$(4,7,8)$. Despite these difficulties, we find that a two factor regression model with body mass $(m$, in $\mathrm{kg}$ ) and $[\mathrm{Mb}]_{\max }(\mathrm{mg} / \mathrm{g})$ as factors yields highly significant predictions of $t_{\max }$ (in s; ordinary least squares regression $P<0.001$ for intercept and slopes, $r^{2} \quad 0.820$, with no significant interaction between factors $P \quad 0.793$ ):

$\log t_{\max } \quad 0.223 \log m+0.972 \log [\mathrm{Mb}]_{\max }+0.891$

The model predicts $82 \%$ of the observed variation in $\log t_{\max }$ among the 42 extant mam mals for which $[\mathrm{Mb}]_{\max }, t_{\max }$, and body mass are available (table S1). The model is not signifi cantly affected when potential phylogenetic ef fects are accounted for (23), indicating that the
Fig. 4. Details of myoglobin net surface charge evolution in major groups of diving mammals. (A) Cetartiodactyla, (B) Carnivora, (C) Rodentia, (D) Eulipotyphla, and (E) Monotremata and Marsupialia. Names of diving and terrestrial species are given in blue and black fonts, respectively. Selected key ( $>|0.20|)$ charge-increasing (blue font) and charge-decreasing (red font) amino acid substitutions are indicated. See fig. S2 for all chargechanging substitutions. Estimated $Z_{M b}$ values of selected extinct species $(\dagger)$ are also indicated. Asterisks mark Mb sequences determined in the present study. Skeletal reconstructions are modified from original publications (table S3).
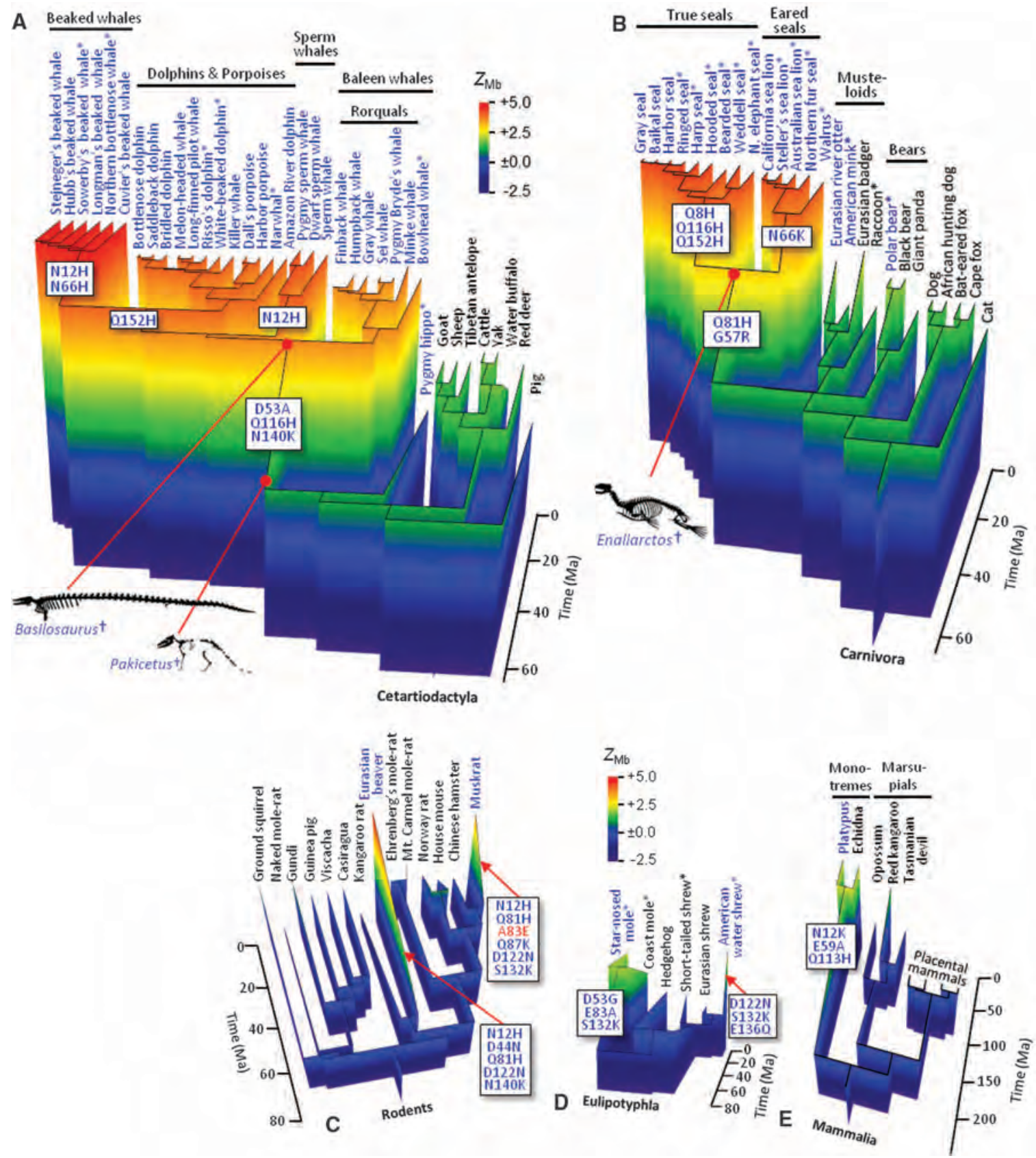
relationship is fundamentally applicable across the mammalian phylogeny. Although variations in lung and blood oxygen stores and diving meta bolic rate $(4,7,8)$ are known to underlie dif ferences in $t_{\max }$ among diving taxa, in the absence of such information we show that body mass and $[\mathrm{Mb}]_{\max }$ together are good markers for the overall net effect of these factors on $t_{\max }$.

Combined with estimates of fossil body mass, our reconstruction of $Z_{\mathrm{Mb}}$ and hence $[\mathrm{Mb}]_{\max }$ (Eq. 1) suggests an order of magnitude increase in $t_{\max }$ during the Eocene land to water transition of whales, from about $1.6 \mathrm{~min}$ in wolf sized, early Eocene Pakicetus to about $17.4 \mathrm{~min}$ in the $6500 \mathrm{~kg}$, late Eocene Basilosaurus (Fig. 6A and table S3). The latter $t_{\max }$ value notably falls within the range of extant oceanic dolphins and rorquals but is still less than a third of the value in similar sized modern beaked whales or the 10 fold larger sperm whale. Because deeper dives take longer and deep foraging mammals generally show the longest maximum dive times $(49,50)$, this suggests that the rich mesopelagic food resources exploited by modern beaked and sperm whales may not yet have been fully available to late Eocene whale ancestors.

Reconstruction of diving capacity in the stem pinniped Enaliarctos yields a $t_{\max }$ value at the lower end of the range found in similar sized modern eared seals that is comparable to the val ue in the threefold smaller Californian sea otter (Fig. 6B). This inference suggests Enaliarctos ex ploited shallow water habitats as opposed to the deep foraging behavior of modern true seals. Within Sirenia, $t_{\max }$ likely changed little since the time of the semiaquatic quadruped Pezosiren $(50 \mathrm{Ma})$ because the gradual reduction in $Z_{\mathrm{Mb}}$ and associated $[\mathrm{Mb}]_{\max }$ was accompanied by an increased body mass that culminated in the gi gantic Steller's sea cow (Figs. 4 and 6C). Increased diving capacity presumably confers little selec tive advantage onto these shallow feeding, slow moving aquatic herbivores. In a rare case of a return from a secondarily semiaquatic to a ter restrial habit, diving capacity within Proboscidea decreased from an estimated $10 \mathrm{~min}$ in late Eocene/ early Oligocene amphibious Moeritherium to about $2.5 \mathrm{~min}$ in terrestrial Asian elephants, consistent with a secondary reduction in $Z_{\mathrm{Mb}}$ and low $[\mathrm{Mb}]_{\max }$ (Figs. 4 and 6C and tables S1 and S2).

\section{Discussion}

Our integrative, comparative evolutionary approach provides insights into a molecular signature of elevated $Z_{\mathrm{Mb}}$ that is found in all elite mammalian divers and correlates with exponential increases in $[\mathrm{Mb}]_{\max }$ and the timing of physiological diving capacity evolution across the major lineages of diving mammals. We show that a simple model based on body mass and maximum muscle $\mathrm{Mb}$ concentration provides very good estimates of maximum dive times in living, and therefore likely also in extinct, mammals across the whole range of diving abilities.

These results give insights into the potential foraging ecologies of early whale and seal ancestors and lead us to hypothesize recent amphibious phases in a number of living terrestrial mammalian lineages, which are open for future testing, for ex ample, by isotope analysis of fossil tooth enamel and examination of fossil limb bone densities (51).

Our results are further consistent with the view that the convergent evolution of high $Z_{\mathrm{Mb}}$ in creases intermolecular electrostatic repulsion of

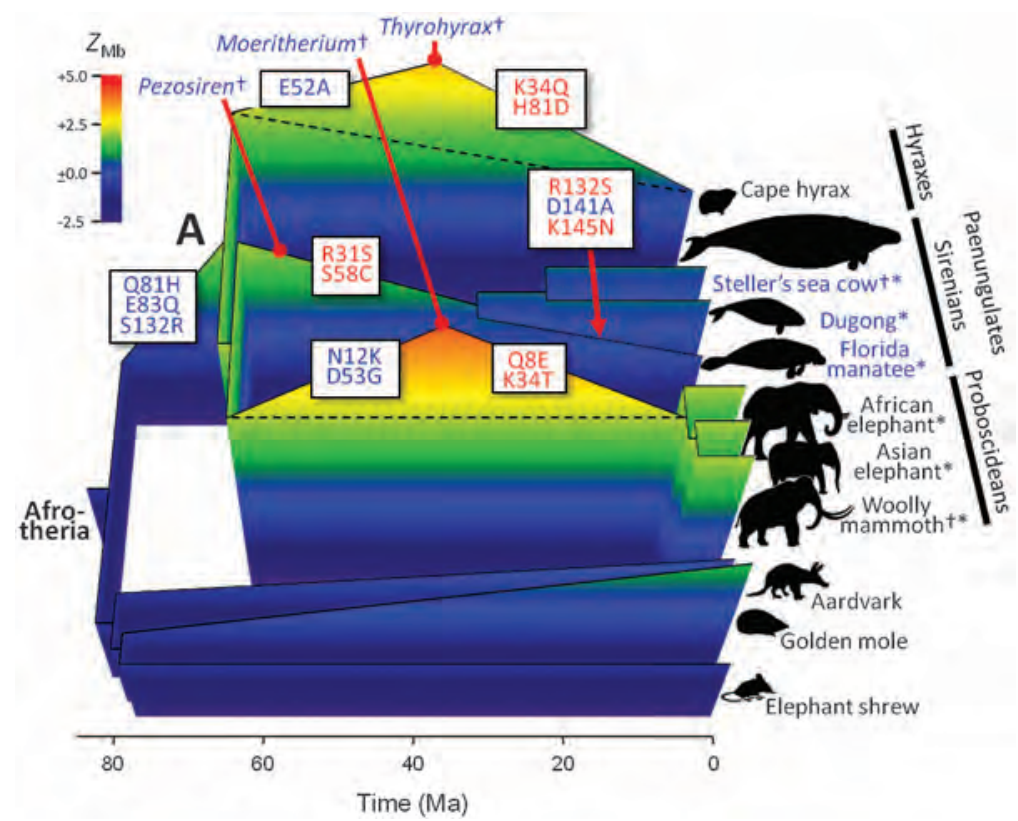

Fig. 5. Evolution of myoglobin net surface charge and aquatic habits in Afrotheria. $Z_{M b}$ values above dashed lines represent our preferred interpretation of the order in which the inferred chargechanging substitutions may have occurred. " $A$ " denotes the inferred shared amphibious ancestor of paenungulates. Other explanations are as in Fig. 4.
$\mathrm{Mb}$ and/or its less stable precursor, apo $\mathrm{Mb}$, per mitting higher oxygen storage capacities in the muscles of mammalian divers without potentially deleterious self association of $\mathrm{Mb}$ or apo $\mathrm{Mb}$. Ac cordingly, aquatic mammals repeatedly evolved a natural form of protein "supercharging," the re combinant introduction of charged amino acid residues for increased protein solubility (52).

Recently, novel roles, such as in hypoxic vasodilation (53) and protection of the hypoxic brain (54), have been proposed for Mb. Integra tion of these and other physiological and bio chemical traits with $\mathrm{Mb}$ sequence evolution across vertebrates may not only reveal mechanisms behind extreme physiological capacities but also im prove our understanding of basic protein structure function relationships.

\section{Materials and Methods}

\section{Body Mass, Maximal Active Dive Time, and Maximal Muscle Mb Concentration}

Mammalian body mass and $t_{\max }$ values were assembled from the literature, taking care to se lect maximum active dive times, i.e., foraging or traveling dives (table $\mathrm{S} 1$ ). $[\mathrm{Mb}]_{\max }$ was determined spectrophotometrically (55) or taken from the lit erature (table $\mathrm{S} 1$ ). In some cases, $[\mathrm{Mb}]_{\max }$ was deter mined by its correlation with muscle iron content obtained from the literature (table S4 and fig. S5).

\section{Mb Net Surface Charge}

$Z_{\mathrm{Mb}}$ was calculated as the sum of the charge of all ionizable groups $(56)$ at $\mathrm{pH} \quad 6.5$ by modeling $\mathrm{Mb}$ primary structures onto the tertiary structure and using published, conserved, site specific ion ization constants or ionization constants we de termined from comparisons of acid base titration curves of Mbs with known residue differences (table S2). In the latter case, Mb from selected species was purified from muscle tissues by using standard protein purification methods, deionized by gel filtration, and titrated as the cyanmetMb derivative under $\mathrm{a} \mathrm{CO}_{2}$ free atmosphere in $0.1 \mathrm{M}$ $\mathrm{KCl}$ at $25^{\circ} \mathrm{C}$ by using $0.1 \mathrm{M} \mathrm{NaOH}$ and $\mathrm{HCl}$ between $\mathrm{pH} \quad 5$ and 9. Unknown $\mathrm{p} K_{\mathrm{a}}$ (where $K_{\mathrm{a}}$ is the acid dissociation constant) values were es timated from the difference in the titration curves obtained for Mbs with and without the ionizable group of interest. In this way, comparison with pig $\mathrm{Mb}$ yielded a $\mathrm{p} K_{\mathrm{a}}$ value of 7.10 for $\mathrm{His}^{88}$ in sheep. Similarly, comparison with dolphin $\mathrm{Mb}$ yielded a $\mathrm{p} K_{\mathrm{a}}$ of 6.07 for His ${ }^{66}$ in beaked whales. The purity of $\mathrm{Mb}$ preparations and the accuracy of modeled $Z_{\mathrm{Mb}}$ values were confirmed by as sessing $\mathrm{Mb}$ electrophoretic mobility on native polyacrylamide gels for selected mammalian spe cies, showing an excellent agreement between electrophoretic mobility and the modeled net sur face charge of $\mathrm{Mbs}$ from terrestrial and aquatic mammals (Fig. 2, A and B).

\section{Mb Sequences from Recent Mammals}

These were obtained from DNA or complementary DNA (cDNA) after polymerase chain reaction 
(PCR) amplification. Ancient DNA from Steller's sea cow and woolly mammoth were obtained from 1000 to 1300 and 28,000 year old mandibles, respectively. See table S5 for sources of all tissue samples.

\section{RNA Extraction for cDNA Synthesis}

Total RNA was extracted from muscle homoge nates by following the Trizol method [Invitrogen (Life Technologies Limited), Paisley, UK]. Con centration and quality of RNA was determined by using a NanoDrop ND 1000 spectrophotometer (Labtech, Uckfield, UK) and by $1.5 \%$ agarose gel electrophoresis. We then used $5 \mu \mathrm{g} / \mu \mathrm{l}$ of total RNA in a standard SuperScript II (Invitrogen) reverse transcriptase reaction to create first strand cDNA. For some species, it was necessary to use $5^{\prime}$ and $3^{\prime}$ rapid amplification of cDNA ends (RACE). For $5^{\prime}$ RACE, the first strand cDNA from the superscript II reaction was poly $\mathrm{C}$ tailed by using terminal transferase (New England Biolabs, Hitchin, UK), and excess primer and nucleotides were removed by using a MinElute PCR Purification Kit (Qiagen, Manchester, UK) according to the manufacturers' instructions. For 3' RACE, first strand cDNA was synthesized by following the SMART method (Clontech, Oxford, UK)

\section{PCR and Sequencing}

$\mathrm{Mb}$ coding sequences were amplified from cDNA by PCR by using forward and reverse primers designed on the basis of consensus alignments in the $5^{\prime}$ and $3^{\prime}$ untranslated regions from closely related species (table $\mathrm{S} 6$ ). Eulipotyphlan $\mathrm{Mb}$ am plification was conducted by using primers to ob tain a core fragment, followed by two $5^{\prime}$ RACE PCRs using a poly $\mathrm{G}$ primer and gene specific reverse primers STSR3 and STSR1 or CMR1, and $3^{\prime}$ RACE, which was conducted by using the SMART primer and the consensus forward primer 3'.Mb.probe, based on a conserved region between position 306 and 326 in mammalian $\mathrm{Mb}$ coding nucleotide sequences. Elephant $\mathrm{Mb}$ exons were amplified separately from genomic DNA (gDNA) by using conserved primers designed by Primer Premier software (version 5, Premier Biosoft, Palo Alto, CA) in the flanking regions (table S6). Partial woolly mammoth Mb sequences were assembled by using Sequencher software (version 4.6, Gene Codes, Ann Arbor, MI) from sequence fragments in the $0.8 \times$ nuclear genome database (http://mammoth.psu.edu) (57) mapped to the Asian elephant. Remaining gene coding re gions were amplified from gDNA in seven frag ments (each 85 to 186 bp in length) by PCR in an ancient DNA dedicated laboratory (McMaster
University, Canada) using primers designed as above (table S6). Successful amplicons were pu rified, ligated into $\mathrm{pDrive}$ vectors, and transformed into EZ Competent cells using a PCR Cloning ${ }^{\text {plus }}$ Kit (Qiagen). Cloned inserts were amplified by a $57^{\circ} \mathrm{C}$ colony PCR using primers $\mathrm{M} 13 \mathrm{~F}$ and M13 R according to a standard PCR protocol (Invitrogen). All PCRs were carried out accord ing to conditions described in table S7, and am plifications were confirmed on 1.5 to $2 \%$ agarose gels. Successful amplicons were purified as above and sequenced on an Applied Biosystems 3130 Genetic Analyzer using a BigDye Terminator v3.1 Cycle Sequencing Kit [Applied Biosystems (Life Technologies Limited), Warrington, UK]. Sequencing reads from elephants and the woolly mammoth were assembled by using Sequencher software (version 4.6), and the amino acid com plement of the $\mathrm{Mb}$ gene was deduced from the consensus sequence.

\section{Design of Sirenian Mb Hybridization Capture Array}

An Agilent 244k SureSelect Capture Array (Agilent Technologies, Santa Clara, CA) was designed to capture the $\mathrm{Mb}$ genes from Florida manatee, $\mathrm{du}$ gong, and the extinct Steller's sea cow. Coding sequences of the $\mathrm{Mb}$ gene (plus $25 \mathrm{bp}$ of up

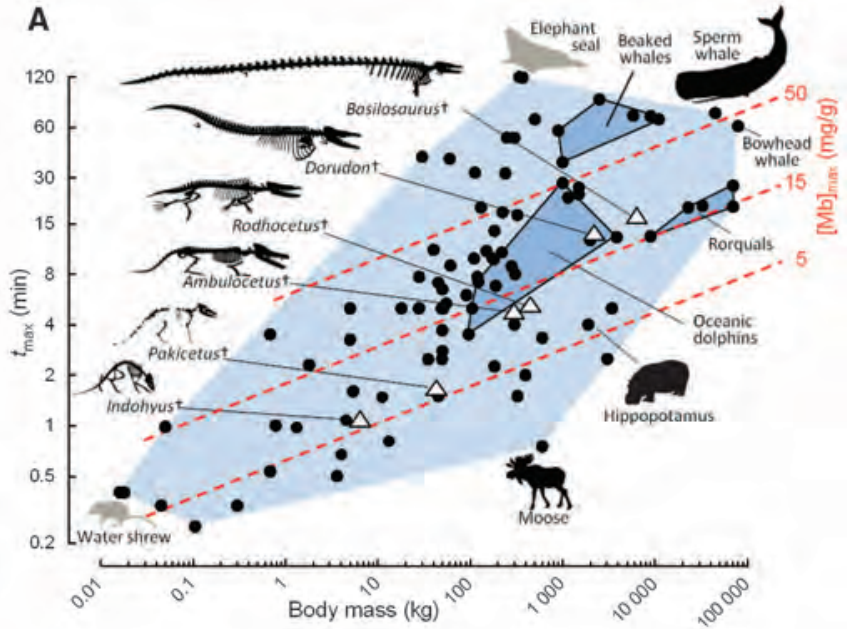

Fig. 6. Modeling diving capacity in ancestral whales, seals, and sea cows. $t_{\max }$ and body mass in extant mammals (circles) and fossil representatives of their land-to-water transitions (triangles). Convex polygons for all mammals (light shading) and selected groups (heavy shading) are indicated. Skeletons, black silhouettes, and solid lines depict selected members of (A) Cetartiodactyla, (B) Carnivora, or (C) Afrotheria. $t_{\max }$ in extinct forms was modeled on the basis of its relationship with body mass and $[\mathrm{Mb}]_{\max }$ in extant mammals (Eq. 2, dashed lines), using ancestral reconstructions of $Z_{\mathrm{Mb}}$ for inferring $[\mathrm{Mb}]_{\max }$ (Eq. 1) and fossil body mass estimates (table S3). Skeletal reconstructions are modified from original publications (table S3).
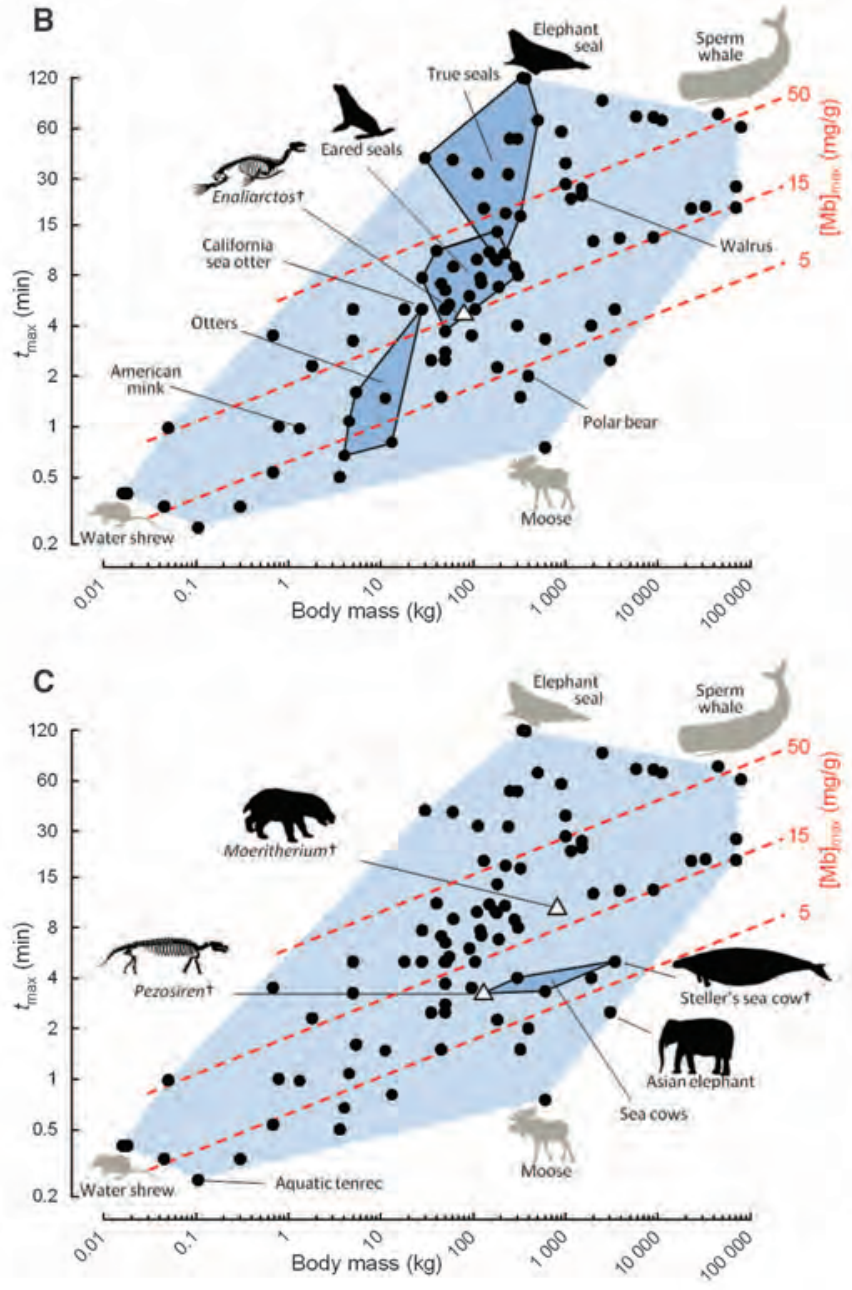
stream and downstream sequence of each of the three exons) mined from the genomic data sets of the African elephant and rock hyrax (GenBank accessions AAGU03077599.1, ABRQ01421420.1, ABRQ01421419.1, and ABRQ01816509.1) were used to design a series of overlapping $60 \mathrm{bp}$ probes ( 1 bp tiling) by using Agilent's eArray tool (earray.chem.agilent.com). Probes were masked of repetitive elements by using RepeatMasker (www.repeatmasker.org) and imprinted on six identical microarrays by Agilent Technologies.

\section{Construction of Indexed Sirenian} DNA Library

Indexed DNA libraries suitable for Illumina (Illumina, San Diego, CA) sequencing were pre pared from gDNA samples (table S5). A $\sim 250 \mathrm{mg}$ bone sample of Steller's sea cow specimen ZI6852 was ground to powder by using mortar and pestle in a dedicated ancient DNA laboratory at the University of York, and DNA was extracted by following the protocol described in Rohland et al. (58). Samples ZI6853 and ZI17170(2) were ex tracted from ground bone samples in an ancient DNA dedicated laboratory in Copenhagen by using the DNeasy Blood and Tissue Kit (Qiagen). Extraction blanks, serving as negative controls, were treated in a similar manner throughout. For the manatee and dugong samples, $200 \mathrm{ng}$ of gDNA was fragmented by using NEBNext dsDNA Fragmentase (New England BioLabs) in $4.0 \mu \mathrm{l}$ reactions, following manufacturer's guidelines. Reactions were promptly purified with an Illustra GFX PCR DNA and Gel Band Purification Kit (GE Healthcare Life Sciences, Pittsburgh, PA). Blunt end repair, adaptor ligation, and adaptor fill in reactions were performed on the fragmented DNA samples as previously described (59); reac tion cleanup was by MinElute PCR purification kit (Qiagen). We added $10 \mu$ of each successful library preparation to indexing PCR reactions; for conditions, see table S7. PCR success was veri fied by $2.5 \%$ agarose gel electrophoresis and am plified products were purified with an Illustra GFX PCR DNA and Gel Band Purification Kit (GE Life Sciences). Purified PCR products were split into four equal volumes and reamplified with primers IS5 reamp.P5 and IS6.reamp.P74, in re actions described for indexing PCR and purified with MinElute as above.

DNA libraries prepared from Steller's sea cow, dugong, and Florida manatee DNA were hy bridized to custom designed capture arrays (60). Captured products were sequenced by Ambry Ge netics (Aliso Viejo, CA) on an Illumina Genome Analyzer IIx using a 54 bp singleton sequencing protocol. Raw Illumina reads were trimmed of adapters and low quality bases and then assem bled to a reference sequence by using Geneious software (Biomatters Limited, Auckland, New Zealand). Because the draft genome of the Florida manatee has recently become publicly available, the complete $\mathrm{Mb}$ gene was mined from this data set (GenBank accession AHIN01036638.1) and used as the reference sequence for the manatee, dugong, and Steller's sea cow Mb assemblies.

In cases where $\mathrm{Mb}$ primary structure deduced from DNA data differed from previously pub lished amino acid sequences (e.g., Asian and African elephant, aardvark), the former was in cluded in the analysis.

\section{Ancestral $\mathrm{Mb}$ Sequences}

These were reconstructed from the aligned $\mathrm{Mb}$ amino acid sequences of 128 extant and two re cently extinct mammals (fig. S4) by the maximum likelihood method as implemented in MEGA5 (61) on a user defined composite, time calibrated mammalian phylogeny that had been assembled from literature data in Mesquite (62) (fig. S6; see supplementary text for sources and the tree in Newick format) (17). Ancestral sequence recon structions used the Dayhoff $+\mathrm{G}$ model, which was determined as best fitting the data according to the model test facilities in MEGA5. Ancestral amino acid reconstructions were generally sup ported by probabilities of more than $90 \%$, such that for ancestral charge reconstructions only the most probable amino acid for each site was con sidered. fig. S2 displays the modeled net charge at all ancestral nodes of the composite mamma lian phylogeny and all inferred charge changing $\mathrm{Mb}$ substitutions over the entire tree.

\section{Modeling Maximal Active Dive Times and Statistics}

We developed two regression models: first using $Z_{\mathrm{Mb}}$ as predictor of $[\mathrm{Mb}]_{\max }$ and second using body mass and $[\mathrm{Mb}]_{\max }$ together as predictors of $t_{\max }$. For these analyses, $[\mathrm{Mb}]_{\max }$, body mass, and $t_{\max }$ were $\log _{10}$ transformed. Because the hierarchical nature of phylogenetic relatedness in multispecies data sets potentially violates the as sumption of statistical independence, we used like lihood ratio tests to determine whether ordinary least squares regression, phylogenetic generalized least squares regression, or regression under an Ornstein Uhlenbeck process best fit our data with the program RegressionV2.m in MATLAB (MathWorks, Nattick, MA) as previously out lined in detail (23). For this, branch lengths of the composite tree (fig. S6) were modified by the method of Nee in Mesquite (62) before analysis in RegressionV2.m. Statistical significance was accepted at $P<0.05$.

$t_{\max }$ in ancestral mammals was modeled by first determining ancestral $Z_{\mathrm{Mb}}$ based on ances tral primary structure reconstruction (see above). $Z_{\mathrm{Mb}}$ was then used to obtain ancestral $[\mathrm{Mb}]_{\max }$, which together with literature data on fossil body mass (table S3) was then used to predict $t_{\max }$, all based on the relationships here established between these parameters in extant mammals (Eqs. 1 and 2).

For comparison, we also used linear parsi mony as implemented in MacClade 4.0 (63) to reconstruct ancestral $[\mathrm{Mb}]_{\max }$ as a continuous valued character, as described before (29), with Carnivora as an example (fig. S3).

\section{References and Notes}

1. S. L. Watwood, P. J. O. Miller, M. Johnson, P. T. Madsen, P. L. Tyack, Deep diving foraging behaviour of sperm whales (Physeter macrocephalus). J. Anim. Ecol. 75, 814 (2006). doi: 10.1111/j.1365 2656.2006.01101.x; pmid: 16689963

2. B. S. Stewart, R. L. Delong, Double migrations of the Northern elephant seal, Mirounga angustirostris. J. Mammal. 76, 196 (1995). doi: 10.2307/1382328

3. T. M. Williams, S. R. Noren, M. Glenn, Extreme physiological adaptations as predictors of climate change sensitivity in the narwhal, Monodon monoceros. Mar. Mamm. Sci. 27, 334 (2011). doi: 10.1111/j.1748 7692.2010.00408.x

4. P. J. Ponganis, ]. U. Meir, C. L. Williams, In pursuit of Irving and Scholander: A review of oxygen store management in seals and penguins. J. Exp. Biol. 214, 3325 (2011). doi: 10.1242/jeb.031252; pmid: 21957096

5. E. Meijaard, Umilaela, G. de Silva Wijeyeratne, Aquatic escape behaviour in mouse deer provides insight into tragulid evolution. Mamm. Biol. Z. Saugetierkd. 75, 471 (2010)

6. M. D. Uhen, Evolution of marine mammals: Back to the sea after 300 million years. Anat. Rec. 290, 514 (2007). doi: 10.1002/ar.20545; pmid: 17516441

7. P. J. Butler, D. R. Jones, Physiology of diving of birds and mammals. Physiol. Rev. 77, 837 (1997). pmid: 9234967

8. G. L. Kooyman, P. ]. Ponganis, The physiological basis of diving to depth: Birds and mammals. Annu. Rev. Physiol. 60, 19 (1998). doi: 10.1146/annurev.physiol.60.1.19; pmid: 9558452

9. G. L. Kooyman, E. A. Wahrenbrock, M. A. Castellini, R. W. Davis, E. E. Sinnett, Aerobic and anaerobic metabolism during voluntary diving in Weddell seals Evidence of preferred pathways from blood chemistry and behavior. J. Comp. Physiol. 138, 335 (1980).

10. S. R. Noren, T. M. Williams, Body size and skeletal muscle myoglobin of cetaceans: Adaptations for maximizing dive duration. Comp. Biochem. Physiol. A Mol. Integr. Physiol. 126, 181 (2000). doi: 10.1016/S1095 6433(00)00182 3; pmid: 10936758

11. K. C. Lestyk, L. P. Folkow, A. S. Blix, M. O. Hammill, J. M. Burns, Development of myoglobin concentration and acid buffering capacity in harp (Pagophilus groenlandicus) and hooded (Cystophora cristata) seals from birth to maturity. J. Comp. Physiol. B 179, 985 (2009). doi: 10.1007/s00360 0090378 9; pmid: 19565249

12. J. C. Kendrew et al., Structure of myoglobin: A three dimensional Fourier synthesis at $2 \mathrm{~A}$. resolution. Nature 185, 422 (1960). doi: 10.1038/185422a0; pmid: 18990802

13. G. Gros, B. A. Wittenberg, T. Jue, Myoglobin's old and new clothes: From molecular structure to function in living cells. J. Exp. Biol. 213, 2713 (2010). doi: 10.1242 jeb.043075; pmid: 20675540

14. E. Antonini, M. Brunori, Hemoglobin and Myoglobin in Their Reactions with Ligands, A. Neuberger, E. L. Tatum, Eds. (Frontiers of Biology, North Holland Publishing Company, Amsterdam, 1971).

15. E. E. Scott, E. V. Paster, J. S. Olson, The stabilities of mammalian apomyoglobins vary over a 600 fold range and can be enhanced by comparative mutagenesis. J. Biol. Chem. 275, 27129 (2000). pmid: 10852902

16. W. C. B. Regis, J. Fattori, M. M. Santoro, M. Jamin, C. H. I. Ramos, On the difference in stability between horse and sperm whale myoglobins. Arch. Biochem. Biophys. 436, 168 (2005). doi: 10.1016/j.abb.2005.01.016; pmid: 15752722

17. Supplementary materials for this article are available on Science Online.

18. C. N. Pace, G. R. Grimsley, ]. M. Scholtz, Protein ionizable groups: $\mathrm{p} K$ values and their contribution to protein stability and solubility. J. Biol. Chem. 284, 13285 (2009). doi: 10.1074/jbc.R800080200; pmid: 19164280

19. A. H. A. Van den Oord, J. J. Wesdorp, A. F. Van Dam, ]. A. Verheij, Occurrence and nature of equine and bovine myoglobin dimers. Eur. J. Biochem. 10, 140 (1969). doi: 10.1111/j.1432 1033.1969.tb00665.x; pmid: 5345978 
20. S. Nagao et al., Structural and oxygen binding properties of dimeric horse myoglobin. Dalton Trans. 41, 11378 (2012). doi: 10.1039/c2dt30893b; pmid: 22885714

21. S. Zorrilla, G. Rivas, A. U. Acuña, M. P. Lillo, Protein self association in crowded protein solutions: A time resolved fluorescence polarization study. Protein Sci. 13, 2960 (2004). doi: 10.1110/ps.04809404; pmid: 15459331

22. ]. B. Wittenberg, Myoglobin facilitated oxygen diffusion: Role of myoglobin in oxygen entry into muscle. Physiol. Rev. 50, 559 (1970). pmid: 4922928

23. S. R. Lavin, W. H. Karasov, A. R. Ives, K. M. Middleton, T. Garland Jr., Morphometrics of the avian small intestine compared with that of nonflying mammals: A phylogenetic approach. Physiol. Biochem. Zool. 81, 526 (2008). doi: 10.1086/590395; pmid: 18754728

24. P. W. Hochachka, P. D. Mottishaw, in Cold Ocean Physiology, H. O. Pörtner, R. C. Playle, Eds. (Cambridge Univ. Press, Cambridge, 1998), pp. 391431.

25. A. Berta, C. E. Ray, A. R. Wyss, Skeleton of the oldest known pinniped, Enaliarctos mealsi. Science 244, 60 (1989). doi: 10.1126/science.244.4900.60; pmid: 17818847

26. R. M. Kramer, V. R. Shende, N. Motl, C. N. Pace, J. M. Scholtz, Toward a molecular understanding of protein solubility: Increased negative surface charge correlates with increased solubility. Biophys. J. 102 1907 (2012). doi: 10.1016/j.bpj.2012.01.060; pmid: 22768947

27. P. J. Reeds, Dispensable and indispensable amino acids for humans. J. Nutr. 130, 1835 S (2000) pmid: 10867060

28. I. W. McIntyre, K. L. Campbell, R. A. MacArthur, Body oxygen stores, aerobic dive limits and diving behaviour of the star nosed mole (Condylura cristata) and comparisons with non aquatic talpids. J. Exp. Biol. 205, 45 (2002). pmid: 11818411

29. M. Berenbrink, P. Koldkjaer, O. Kepp, A. R. Cossins, Evolution of oxygen secretion in fishes and the emergence of a complex physiological system. Science 307, 1752 (2005). doi: 10.1126/science.1107793; pmid: 15774753

30. M. Berenbrink, Evolution of vertebrate haemoglobins: Histidine side chains, specific buffer value and Bohr effect. Respir. Physiol. Neurobiol. 154, 165 (2006) doi: 10.1016/j.resp.2006.01.002; pmid: 16481225

31. M. J. Phillips, T. H. Bennett, M. S. Lee, Molecules, morphology, and ecology indicate a recent, amphibious ancestry for echidnas. Proc. Natl. Acad. Sci. U.S.A. 106 17089 (2009). doi: 10.1073/pnas.0904649106; pmid: 19805098

32. B. Campbell, The shoulder anatomy of the moles. A study in phylogeny and adaptation. Am. J. Anat. 64, 1 (1939) doi: 10.1002/aja.1000640102

33. P. W. Hochachka, J. Baldwin, R. I. Griffiths, Metabolic adaptations and responses of the echidna to burrowing. Mol. Physiol. 5, 165 (1984)

34. A. G. Liu, E. R. Seiffert, E. L. Simons, Stable isotope evidence for an amphibious phase in early proboscidean evolution. Proc. Natl. Acad. Sci. U.S.A. 105, 5786 (2008). doi: 10.1073/pnas.0800884105: pmid: 18413605

35. C. W. Andrews, A Descriptive Catalogue of the Tertiary Vertebrata of the Fayum, Egypt: Based on the Collection of the Egyptian Government in the Geological Museum, Cairo, and on the Collection in the British Museum (Natural History) [Trustees of the British Museum (Natural History), London, 1906].

36. H. F. Osborn, Proboscidea (American Museum, New York 1936), vol. 1
37. M. T. Clementz, P. A. Holroyd, P. L. Koch, Identifying aquatic habits of herbivorous mammals through stable isotope analysis. Palaios 23, 574 (2008). doi: 10.2110/palo.2007.p07 054r

38. E. R. Seiffert, A new estimate of afrotherian phylogeny based on simultaneous analysis of genomic, morphological, and fossil evidence. BMC Evol. Biol. 7, 224 (2007). doi: 10.1186/1471 21487 224; pmid: 17999766

39. H. F. Osborn, in Proceedings of the Fourth International Congress of Zoology, Cambridge, 1898, A. Sedgwick, Ed. (C. J. Clay and Sons, London, 1899), pp. 172173.

40. M. S. Fischer, Hyracoidea, in Vol. VIII: Mammalia, in Handbuch der Zoologie, ]. Niethammer, H. Schliemann, D. Starck, Eds. (De Gruyter, Berlin, 1992).

41. R. W. Meredith et al., Impacts of the Cretaceous Terrestrial Revolution and $\mathrm{KPg}$ extinction on mammal diversification. Science 334, 521 (2011); 10.1126/science.1211028. doi: 10.1126/science.1211028; pmid: 21940861

42. G. T. Schwartz, D. T. Rasmussen, R. J. Smith, Body size diversity and community structure of fossil hyracoids. J. Mammal. 76, 1088 (1995). doi: 10.2307/1382601

43. N. N. Court, Morphology and functional anatomy of the postcranial skeleton of Arsinoitherium. Palaeontogr. Abt. A Palaeozool. Stratigr. 226, 125 (1993).

44. D. P. Domning, The earliest known fully quadrupedal sirenian. Nature 413, 625 (2001). doi: 10.1038/35098072; pmid: 11675784

45. T. M. Williams, The evolution of cost efficient swimming in marine mammals: Limits to energy optimization. Philos. Trans. R. Soc. London B Biol. Sci. 354, 193 (1999). doi: 10.1098/rstb.1999.0371

46. P. F. Scholander, L. Irving, Experimental investigations on the respiration and diving of the Florida manatee. J. Cell. Comp. Physiol. 17, 169 (1941). doi: 10.1002/ jcp.1030170204

47. G. J. Gallivan, J. W. Kanwisher, R. C. Best, Heart rates and gas exchange in the Amazonian manatee (Trichechus inunguis) in relation to diving. J. Comp. Physiol. B 156 , 415 (1986).doi: 10.1007/BF01101104; pmid: 3088073

48. G. W. Steller, De bestiis marinis. Novi commentarii Academiae Scientiarvm Imperialis Petropolitanae 2289 (1751); http://gdz.sub.uni goettingen.de/index.php?id= 11\&PPN=PPN350003793\&DMDID=DMDLOG 0025\&LOGID=LOG 0025\&PHYSID=PHYS 0322\&L=1.

49. L. G. Halsey, P. ]. Butler, T. M. Blackburn, A phylogenetic analysis of the allometry of diving. Am. Nat. 167, 276 (2006). doi: 10.1086/499439; pmid: 16670986

50. J. F. Schreer, K. M. Kovacs, Allometry of diving capacity in air breathing vertebrates. Can. J. Zool. 75, 339 (1997). doi: 10.1139/z97 044

51. J. G. Thewissen, L. N. Cooper, M. T. Clementz, S. Bajpai, B. N. Tiwari, Whales originated from aquatic artiodactyls in the Eocene epoch of India. Nature 450, 1190 (2007). doi: 10.1038/nature06343; pmid: 18097400

52. M. S. Lawrence, K. J. Phillips, D. R. Liu, Supercharging proteins can impart unusual resilience. J. Am. Chem. Soc. 129, 10110 (2007). doi: 10.1021/ja071641y; pmid: 17665911

53. M. Totzeck et al., Nitrite regulates hypoxic vasodilation via myoglobin dependent nitric oxide generation. Circulation 126, 325 (2012). doi: 10.1161 CIRCULATIONAHA.111.087155; pmid: 22685116

54. S. Helbo et al., Functional differentiation of myoglobin isoforms in hypoxia tolerant carp indicates tissue specific protective roles. Am. J. Physiol. Regul. Integr. Comp. Physiol. 302, R693 (2012). doi: 10.1152/ajpregu.00501.2011; pmid: 22170621

55. B. Reynafarje, Simplified method for the determination of myoglobin. J. Lab. Clin. Med. 61, 138 (1963). pmid 13981912
56. T. McLellan, Molecular charge and electrophoretic mobility in cetacean myoglobins of known sequence. Biochem. Genet. 22, 181 (1984). doi: 10.1007/ BF00499297; pmid: 6712587

57. W. Miller et al., Sequencing the nuclear genome of the extinct woolly mammoth. Nature 456, 387 (2008). doi: 10.1038/nature07446; pmid: 19020620

58. N. Rohland, H. Siedel, M. Hofreiter, A rapid column based ancient DNA extraction method for increased sample throughput. Mol. Ecol. Resour. 10, 677 (2010). doi: 10.1111/j.1755 0998.2009.02824.x pmid: 21565072

59. M. Meyer, M. Kirchner, Illumina sequencing library preparation for highly multiplexed target capture and sequencing. Cold Spring Harb. Protoc. 2010, (2010). doi: 10.1101/pdb.prot5448; pmid: 20516186

60. E. Hodges et al., Hybrid selection of discrete genomic intervals on custom designed microarrays for massively parallel sequencing. Nat. Protoc. 4, 960 (2009). doi: 10.1038/nprot.2009.68; pmid: 19478811

61. K. Tamura et al., MEGA5: Molecular evolutionary genetics analysis using maximum likelihood, evolutionary distance, and maximum parsimony methods. Mol. Biol. Evol. 28, 2731 (2011). doi: 10.1093/molbev/msr121; pmid: 21546353

62. W. P. Maddison, D. R. Maddison, Mesquite: A Modula System for Evolutionary Anlysis, version 2.75 (2011), http://mesquiteproject.org.

63. D. R. Maddison, W. P. Maddison, MacClade 4: Analysis of Phylogeny and Character Evolution (Sinauer Associates, Sunderland, MA, 2000).

Acknowledgments: We thank ]. Lecomte, J. B. Wittenberg, H. Mitcheson, K. Arbuckle, D. Rigden, ]. A. Green, ]. A. Rees, and S. Völkel for discussions and comments; P. Koldkjær M. Wilkinson, and D. Williams for technical advice; and M. Hofreiter, ]. Paijmans, H. Poinar, and ]. Enk for assistance with ancient DNA sequencing. We further thank E. Arnason, ]. Barnett, N. Davison, R. Deaville, R. Debruyne, S. Ferguson, E. Flach, X. Lambin, R. MacPhee, D. McCafferty, L. Moore, H. Pauleickhoff, R. Stewart, K. Wareing, E. Willerslev, and the Zoological Society of London for tissue samples. All sequences obtained in this study have been submitted to GenBank under the accession numbers KC524735 to KC524769, and all individual species data and sources are listed in the supplementary materials (17). Financial support was provided by the Biotechnology and Biological Sciences Research Council, UK (S.M., M.B.), the University of Manitoba Research Grant Program (K.L.C.), the Natural Sciences and Engineering Research Council (NSERC) of Canada (K.L.C.). M.B. conceived the project; S.M. and M.B. developed and organized the project with input from A.R.C. and K.L.C.; S.M., A.V.S., and J.M.B. performed experiments. S.M., K.L.C., A.R.C., and M.B. analyzed data. S.M. and M.B. drafted the manuscript. All authors contributed to final manuscript preparation, discussed the results and their implications, and have read and approved the final manuscript.

\section{Supplementary Materials}

www.sciencemag.org/content/340/6138/1234192/suppl/DC1 Supplementary Text

Figs. S1 to $\mathrm{S} 6$

Tables S1 to $\mathrm{S7}$

References (64 249)

17 December 2012; accepted 29 April 2013 10.1126/science. 1234192 